\title{
Synthesis, characterization, and antimicrobial activity of an ampicillin-conjugated magnetic nanoantibiotic for medical applications
}

This article was published in the following Dove Press journal:

International Journal of Nanomedicine

8 August 2014

Number of times this article has been viewed

\author{
Samer Hasan Hussein-Al-Ali ${ }^{1,2}$ \\ Mohamed Ezzat El \\ Zowalaty ${ }^{3,4}$ \\ Mohd Zobir Hussein ${ }^{5}$ \\ Benjamin M Geilich ${ }^{6}$ \\ Thomas J Webster ${ }^{6,7}$ \\ 'Laboratory of Molecular \\ Biomedicine, ${ }^{2}$ Faculty of Pharmacy, \\ Isra University, Amman, Kingdom of \\ Jordan; ${ }^{3}$ Laboratory of Vaccines and \\ Immunotherapeutics, Institute of \\ Bioscience, Universiti Putra Malaysia, \\ Serdang, Selangor, Malaysia; ${ }^{4}$ Faculty of \\ Public Health and Tropical Medicine, \\ Jazan University, Jazan, Kingdom of \\ Saudi Arabia; ${ }^{5}$ Materials Synthesis \\ and Characterization Laboratory \\ Institute of Advanced Technology, \\ Universiti Putra Malaysia, Serdang, \\ Selangor, Malaysia; ${ }^{6}$ Department of \\ Chemical Engineering and Program \\ in Bioengineering, Northeastern \\ University, Boston, MA, USA $;{ }^{7}$ Center \\ of Excellence for Advanced Materials \\ Research, King Abdulaziz University, \\ Jeddah, Kingdom of Saudi Arabia
}

Correspondence: Mohd Zobir Hussein Materials Synthesis and Characterization Laboratory, Institute of Advanced Technology, University Putra Malaysia, Selangor-43400, Malaysia

Tel $+6038946680 \mathrm{I}$

Fax +60389435380

Email mzobir@upm.edu.my
Abstract: Because of their magnetic properties, magnetic nanoparticles (MNPs) have numerous diverse biomedical applications. In addition, because of their ability to penetrate bacteria and biofilms, nanoantimicrobial agents have become increasingly popular for the control of infectious diseases. Here, MNPs were prepared through an iron salt coprecipitation method in an alkaline medium, followed by a chitosan coating step (CS-coated MNPs); finally, the MNPs were loaded with ampicillin (amp) to form an amp-CS-MNP nanocomposite. Both the MNPs and amp-CS-MNPs were subsequently characterized and evaluated for their antibacterial activity. X-ray diffraction results showed that the MNPs and nanocomposites were composed of pure magnetite. Fourier transform infrared spectra and thermogravimetric data for the MNPs, CS-coated MNPs, and amp-CS-MNP nanocomposite were compared, which confirmed the CS coating on the MNPs and the amp-loaded nanocomposite. Magnetization curves showed that both the MNPs and the amp-CS-MNP nanocomposites were superparamagnetic, with saturation magnetizations at 80.1 and $26.6 \mathrm{emu} \mathrm{g}^{-1}$, respectively. Amp was loaded at $8.3 \%$. Drug release was also studied, and the total release equilibrium for amp from the amp-CS-MNPs was $100 \%$ over 400 minutes. In addition, the antimicrobial activity of the amp-CS-MNP nanocomposite was determined using agar diffusion and growth inhibition assays against Gram-positive bacteria and Gram-negative bacteria, as well as Candida albicans. The minimum inhibitory concentration of the amp-CS-MNP nanocomposite was determined against bacteria including Mycobacterium tuberculosis. The synthesized nanocomposites exhibited antibacterial and antifungal properties, as well as antimycobacterial effects. Thus, this study introduces a novel $\beta$-lactam antibacterial-based nanocomposite that can decrease fungus activity on demand for numerous medical applications.

Keywords: iron oxide nanoparticles, chitosan, coating material, antibacterial activity, $\beta$-lactam, and nanoantibiotics

\section{Introduction}

Iron oxide magnetic nanoparticles (MNPs) with the general formula $\mathrm{Fe}_{3} \mathrm{O}_{4}$ are suitable for biomedical applications because of their unique properties, such as biological properties, superparamagnetic behavior, external control, hypothermal behavior when stimulated, and controllable parameters. ${ }^{1-5}$ Because of their exceptional properties, researchers have attempted to use such nanoparticles for tumor inhibition, ${ }^{6}$ dual-functional probes, ${ }^{7}$ and antibacterial agents. ${ }^{6}$ Although different biomedical applications for various iron oxide MNPs (such as drug delivery, ${ }^{7}$ cellular labeling/cell separation, ${ }^{8}$ tissue repair, ${ }^{9}$ magnetic resonance imaging, ${ }^{9}$ and magnetic hyperthermia) $)^{10}$ have been studied by several research groups, it is essential to determine their toxicity in animal models. Mahmoudi et al studied the cytotoxicity of 
polyvinyl alcohol-coated magnetic nanoparticles in mouse fibroblast cells and a human leukemia cell line, with results highlighting that at appropriate concentrations, MNPs are not toxic. ${ }^{11}$ Similar to that, certain MNPs have been approved by the US Food and Drug Administration for enhancing magnetic resonance image (MRI) and have been injected not only in animals but also in 14 patients (through intravenous injection very close to a tumor site) for targeting anticancer drugs (such as doxorubicin derivatives). ${ }^{12,13}$ Thus, as with any material, it is important to be below toxic concentrations of MNPs for a proposed biomedical application.

However, the use of MNPs for treating infections has not been widely reported to date. In contrast, antibiotics are a cornerstone of the modern medicine area. ${ }^{14} \beta$-lactam antibiotics are one of the oldest and largest classes of a broad spectrum of antimicrobial chemotherapeutic agents to be used clinically because of their excellent pharmacokinetic properties (compared with their additional antibiotic classes) and irreversible bactericidal activity. ${ }^{15}$ Since the discovery of the prototype $\beta$-lactam, ${ }^{16}$ different derivatives have been introduced, such that the $\beta$-lactam pool is currently a diverse class of antimicrobial agents. ${ }^{17}$ Ampicillin (amp) $(6[\mathrm{D}(-)$ - $\alpha$-aminophenylacetamido $]$ penicillanic acid) was the first $\beta$-lactam identified with a broad spectrum of bactericidal activity. ${ }^{18,19}$

Antibiotics, including $\beta$-lactams, are clinically useful because of their overwhelming interplay with bacterial resistance mechanisms, ${ }^{20,21}$ which has motivated antibiotic researchers to pursue more stable modified derivatives. However, the process of drug discovery for new antibiotics or highly stable mimics for current antibiotics, including $\beta$-lactams, is too slow to cope with the escalating and ongoing arsenal of antimicrobial resistance mechanisms in bacteria. ${ }^{22-25}$ Such concerns are evident in an agreement recently approved by the US Food and Drug Administration and in the annually declining clinically useful antibiotic pipeline, which is approaching emptiness. ${ }^{26,27}$ The increasing emergence of antimicrobial resistance warrants the need for the development of more effective broad-spectrum antibacterial agents.

Therefore, nanotechnology (or the use of materials with at least one dimension less than $100 \mathrm{~nm}$ ) advances could restore and rescue the currently available in-hand antibiotics by focusing on improved delivery methods and by localizing release to reduce adverse effects. Nanotechnology is a rapidly emerging field that uses advances in chemistry and engineering to design new agents that affect human health. ${ }^{28}$ Advances in nanotechnology may lead to breakthroughs in nanopharmaceutical antimicrobial agent development, which may provide for public health threats from infectious diseases and associated antimicrobial resistance. ${ }^{29,30}$

Compared with free analogs, nanoparticle-based antimicrobial agents exhibit several advantages, ${ }^{26}$ including their inhibitory and/or killing effect on various microorganisms. These effects are exerted through interactions with microbial cells either directly by disrupting/penetrating the cell envelope, secondary agent production, heavy metal ion dissolution, transmembrane electron transfer disturbance, or indirectly as potent carriers for additional substances with intrinsic antimicrobial properties, which facilitates their targeted delivery and elevated influx inside microbial cells. ${ }^{31-33}$

Previous studies throughout the literature have applied lipid-based approaches (liposomes, solid lipid nanoparticles, nanoemulsions, and microemulsions) and polymerbased nanocarriers (nanocapsules and nanospheres) to enhance the antimicrobial activity of antibiotics (including $\beta$-lactams). ${ }^{34-39}$ Nanoantimicrobial agent synthesis studies have recently increased in number; however, most of these agents are nonantibiotic-based nanoparticles, primarily metal-based nanoparticles that use silver, copper, and zinc, among other metals. This study aimed to prepare the first amp-chitosan-iron oxide nanocomposite for numerous applications such as a novel nanoantibiotic pharmaceutical agent to combat various bacterial diseases.

\section{Materials and methods Materials}

The chemicals in this study were reagent grade and were used as received without purification. Ferrous chloride tetrahydrate $\left(\mathrm{FeCl}_{2} \cdot 4 \mathrm{H}_{2} \mathrm{O}\right)$, ferric chloride hexahydrate $\left(\mathrm{FeCl}_{3} \cdot 6 \mathrm{H}_{2} \mathrm{O}\right)$, and sodium hydroxide $(\mathrm{NaOH})$ were purchased from Merck KGaA (Darmstadt, Germany). Chitosan, deacetylated at $75 \%-85 \%$, sodium amp salt ( $>98 \%$ purity; molecular weight $371.4 \mathrm{~g} / \mathrm{mol}$ ), 4-amino salicylic acid, isonicotinic acid hydrazide, and pyrazinamide were purchased from Sigma-Aldrich Co. (St Louis, MO, USA). Acetic acid (99.8\%) was purchased from Hamburg Industries (Hamburg, Germany). Deionized water was used in each experiment.

\section{Preparing iron oxide nanoparticles}

The MNPs were prepared through coprecipitation, as previously described. ${ }^{40}$ The MNPs were prepared by coprecipitating ferrous and ferric ion salts in an alkaline solution at room temperature. Briefly, a solution was generated by dissolving $\mathrm{Fe}^{2+}(0.3 \mathrm{M})$ and $\mathrm{Fe}^{3+}(0.15 \mathrm{M})$ in deionized water. The mixing solution was added to $200 \mathrm{~mL}$ of $2.0 \mathrm{M} \mathrm{NaOH}$, and 
the color of the mixture was black. The mixture is represented by the following reaction:

$$
2 \mathrm{Fe}^{3+}+\mathrm{Fe}^{2+}+8 \mathrm{OH}^{-} \rightarrow \mathrm{Fe}_{3} \mathrm{O}_{4} \downarrow+4 \mathrm{H}_{2} \mathrm{O}
$$

The MNPs were collected as a powder on separation through centrifugation and were then dried at $50^{\circ} \mathrm{C}$.

\section{Preparing Chitosan-MNPs}

The chitosan (CS)-MNPs were prepared as previously described. ${ }^{41}$ Briefly, a CS solution was prepared by dissolving $0.5 \mathrm{~g}$ CS powder in a $1 \%$ acetic acid solution. The CS-MNPs were prepared by mixing CS with a suspension of $\mathrm{Fe}_{3} \mathrm{O}_{4}$ nanoparticles. After the mixture was stirred and mixed over the course of 18 hours, the CS-MNPs were separated using a permanent magnet and dried at $70^{\circ} \mathrm{C}$ for 2 hours.

\section{Preparing the amp-CS-MNP nanocomposite}

Amp (0.35 g) was dissolved in water. The amp-CS-MNP nanocomposites were prepared by mixing the amp solution with a known mass of each CS-MNP sample. The solution was magnetically stirred at room temperature for 18 hours to facilitate amp uptake. The particles loaded with amp (ampCS-MNPs) were separated, using a permanent magnet.

\section{Amp loading and release quantities for the amp-CS-MNP nanocomposite}

The level of amp loaded in the nanocomposite was determined using a Lambda 35 ultraviolet-visible spectrophotometer (PerkinElmer Inc., Waltham, MA, USA). A known weight of the nanocomposite was placed in a $10 \mathrm{~mL}$ volumetric flask, to which phosphate-buffered saline (PBS) was added. The concentration of amp in the solution was determined at a maximum wavelength $\left(\lambda_{\max }\right)$ of $268 \mathrm{~nm}$, using a standard curve from a series of standard solutions with known amp concentrations.

The level of amp released from the nanocomposite was measured at room temperature in a PBS solution at $0.01 \mathrm{~mol}$ and $\mathrm{pH}$ 7.4. Approximately $85 \mathrm{mg}$ of the nanocomposite was added to $500 \mathrm{~mL}$ of PBS. The release medium $(3 \mathrm{~mL})$ was removed for analysis at given time intervals and replaced with $3 \mathrm{~mL}$ of a buffered solution. The cumulative amp released into the solution was measured in real time at a $\lambda_{\text {max }}$ of $268 \mathrm{~nm}$, using the PerkinElmer spectrophotometer.

The amp release rate from the amp-CS-MNP nanocomposite was compared with that of a physical mixture containing amp with a polymer and the MNPs. Approximately $3.0 \mathrm{mg}$ of the physical mixture was generated by mixing $0.249 \mathrm{mg}$ amp with $0.078 \mathrm{mg} C S$ and $2.673 \mathrm{mg}$ MNPs. The amp release was measured as described earlier.

\section{Microorganisms and antimicrobial activity of the amp-CS-MNP nanocomposite}

Five bacterial strains were used to screen the antibacterial activity for the synthesized amp-CS-MNP nanocomposite: two Gram-positive (methicillin-resistant Staphylococcus aureus and Bacillus subtilis) and three Gram-negative (Escherichia coli, Salmonella choleraesuis, and Pseudomonas aeruginosa) bacterial species. The bacteria were collected from the microbial culture collection unit at the Institute of Bioscience, Universiti Putra, Malaysia. The bacterial cultures were maintained on Luria-Bertani agar (Sigma-Aldrich). Before incubation with the novel nanoparticles, the bacteria were cultured overnight in $5 \mathrm{~mL}$ Luria-Bertani broth (Sigma-Aldrich) in a Certomat BS-T incubation shaker (Sartorius Stedim Biotech, Aubagne, France) at $37^{\circ} \mathrm{C}$ and $150 \mathrm{rpm}$ until the culture reached an optical density measured at a wavelength of $600 \mathrm{~nm}$ of 1.0 (Spekol UV VIS 3.02; Analytic Jena, Jena, Germany), which corresponds to $10^{8}$ colony forming units $(\mathrm{CFU}) \times \mathrm{mL}^{-1}$.

The antimicrobial activities for amp and the synthesized amp-CS-MNP nanocomposite were evaluated against the bacteria described earlier, using the agar diffusion (cup diffusion) method, in accordance with the Clinical and Laboratory Standards Institute guidelines, as previously described. ${ }^{42}$ Briefly, $20 \mathrm{~mL}$ of a liquid Muller Hinton (Sigma-Aldrich) agar ( $\mathrm{pH} 7.3 \pm 0.2$ at $25^{\circ} \mathrm{C}$ ) was poured onto disposable sterilized Petri dishes and solidified. The solidified agar plate surfaces were dried in an incubator before streaking the microorganisms onto the agar plate surfaces. Next, $100 \mu \mathrm{L}$ of the microbial culture suspension in Luria-Bertani broth was streaked over the dried surface of the agar plates and spread uniformly, using a sterilized glass rod; the plates were then dried. The amp-CS-MNPs were suspended in sterile distilled water; two wells were then created in the agar plates, using a sterilized cork borer, and the two wells were filled with the nanoparticle suspensions and free amp solution as a control. The experiment was performed in triplicate, and the zone of inhibition diameters was measured to the nearest millimeter, using a caliper after a 24 -hour incubation at $37^{\circ} \mathrm{C}$.

\section{Microbial growth inhibition}

To quantitatively evaluate the effect of the amp-CS-MNP on the growth kinetics of different microorganisms, the plate colony counting method was employed. Before treatment with the amp-CS-MNPs, bacterial cultures of $S$. aureus $\left(\mathrm{ATCC}^{\circledR} 43300^{\mathrm{TM}}\right)$, P. aeruginosa $\left(\mathrm{ATCC}^{\circledR} 27853^{\mathrm{TM}}\right)$, 
E. coli $\left(\mathrm{ATCC}^{\circledR} 25922^{\mathrm{TM}}\right.$ ), and C. albicans $\left(\mathrm{ATCC}^{\circledR} 20408^{\mathrm{TM}}\right.$ ) were obtained from the American Type Culture Collection (ATCC, Manassas, VA, USA) and were hydrated and streaked for isolation on a tryptic soy agar plate. After growth, a single isolated colony was selected and used to inoculate $3 \mathrm{~mL}$ of $20 \%$ tryptic soy broth media. The bacterial culture was grown on a shaking incubator set at $200 \mathrm{rpm}$ for 18 hours at $37^{\circ} \mathrm{C}$. The resulting bacterial suspension was then adjusted to have an optical density measured at a wavelength $(\lambda)$ of $600 \mathrm{~nm}$ of 1.0 , corresponding to a bacterial density of $10^{8} \mathrm{CFU} / \mathrm{mL}$. Then, the bacterial suspension was serially diluted over a 4-log range to a bacterial density of $10^{4} \mathrm{CFU} / \mathrm{mL}$, using $20 \%$ tryptic soy broth. A volume of $1 \mathrm{~mL}$ of the bacterial suspension was treated with the nanocomposite suspension at a concentration of $10 \mathrm{mg} / \mathrm{mL}$ and $20 \mathrm{mg} / \mathrm{mL}$ in a separate well of a $24-w e l l$ plate and was allowed to incubate for 1 hour at $37^{\circ} \mathrm{C}$. The number of $\mathrm{CFU}$ after treatment was determined using the plate counting method after plating on tryptic soy agar plates. The experiment was repeated in triplicate. The percentage of inhibition of the amp-CS-MNP nanocomposite against each microorganism was calculated as described previously ${ }^{43}$ according to Equation 1:

$$
\text { inhibition rate }=1-\left[\mathrm{CFU}_{\text {treated }} / \mathrm{CFU}_{\text {control }}\right] \times 100 \text {. }
$$

The efficiency of the nanoparticles that inhibited the growth of microorganisms was determined by differences in the equivalent number of CFU before and after treatment as the percentage of microbes that were inhibited by the particles; this was calculated from the previous equation.

\section{Determination of the minimum inhibitory concentration}

The minimum inhibitory concentration (MIC) values of the amp-CS-MNP nanocomposite against the microorganisms (as mentioned in "Microbial growth inhibition") were determined using the broth microdilution method. The microbial suspensions were prepared as described earlier. The MIC was determined over a range of $2,000 \mu \mathrm{g} / \mathrm{mL}$ and $10 \mu \mathrm{g} / \mathrm{mL}$ by the serial dilution method, as described earlier. ${ }^{42}$

\section{Evaluation of the activity of amp-CS-MNPs against Mycobacterium tuberculosis, using MGIT 960}

We employed drug susceptibility testing of amp-CS-MNPs, using the BBL ${ }^{\text {TM }}$ Mycobacteria Growth Indicator Tube (MGITTM) 960 assay against Mycobacterium tuberculosis $\left(\mathrm{ATCC}^{\circledR} 25618^{\mathrm{TM}}\right.$ ), and the MIC of the amp-CS-MNP nanocomposite was determined. The MGIT ${ }^{\mathrm{TM}}$ with BACTEC ${ }^{\mathrm{TM}}$ MGITTM 960 growth supplement for drug susceptibility testing was used in the MGIT 960 instrument (Becton Dickinson Diagnostic Systems, Sparks, MD, USA). The standard protocol for drug susceptibility testing in MGIT 960 was strictly followed, as recommended for primary drugs.

\section{Instrumentation}

Powder X-ray diffraction (XRD) patterns were used to determine the crystal structures of the samples over a range of $20^{\circ}-70^{\circ}$, using an XRD-6000 diffractometer (Shimadzu, Tokyo, Japan) with $\mathrm{CuK} \alpha$ radiation $(\lambda 1.5406 \AA)$ at $30 \mathrm{kV}$ and $30 \mathrm{~mA}$. Fourier transform infrared (FTIR) spectra of the materials were recorded over a range of $400-4,000 \mathrm{~cm}^{-1}$, using a Nexus, Smart Orbit spectrometer (Thermo FisherScientific, Waltham, MA, USA) and the $\mathrm{KBr}$ disk method. Thermogravimetric analyses (TGAs) were performed using a Mettler-Toledo 851e instrument (Mettler-Toledo, Columbus, $\mathrm{OH}, \mathrm{USA}$ ), with a heating rate of $10^{\circ} \mathrm{C} /$ minute in $150 \mu \mathrm{L}$ alumina crucibles over a range of $30^{\circ} \mathrm{C}-900^{\circ} \mathrm{C}$. A CHNS-932 (Leco, St Joseph, MI, USA) instrument was used to analyze carbon, hydrogen, nitrogen, and sulfur. A NOVA $^{\text {TM }}$ NanoSEM 230 (FEI, Hillsboro, OR, USA) scanning electron microscope (SEM) was used to observe the surface morphologies of the samples. The magnetic properties were evaluated using a Lake Shore 7404 vibrating sample magnetometer (Lake Shore Cryotronics, Inc., Westerville, OH, USA). Ultraviolet-visible spectra were generated both to determine the optical properties and for controlled release studies, using an ultraviolet-visible spectrophotometer (PerkinElmer).

\section{Results and discussion XRD}

Figure 1A-C shows XRD patterns for the MNPs, CSMNPs, and amp-CS-MNP nanocomposite, respectively. Six characteristic peaks between $20^{\circ}$ and $70^{\circ}\left(2 \theta=30.1^{\circ}\right.$, $35.5^{\circ}, 43.1^{\circ}, 53.5^{\circ}, 57.2^{\circ}$, and $\left.62.7^{\circ}\right)$ with indices of ([2 20$]$,

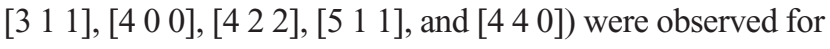
the MNPs, CS-MNPs, and amp-CS-MNP nanocomposite. The peaks were consistent with the database and Joint Committee on Powder Diffraction Standards file (card 19-0629), confirming that the nanoparticles were pure $\mathrm{Fe}_{3} \mathrm{O}_{4}$ with a spinel structure. The MNPs have a face-centered cubic crystal structure with a lattice constant (a) of $8.38 \AA$, and our results agree in value, with $\mathrm{a}=8.39 \AA .^{44}$ The mean grain size was calculated using the Debye-Scherrer formula, as shown in Equation 2.

$$
\mathrm{D}=\frac{k \lambda}{\beta \cos \theta},
$$




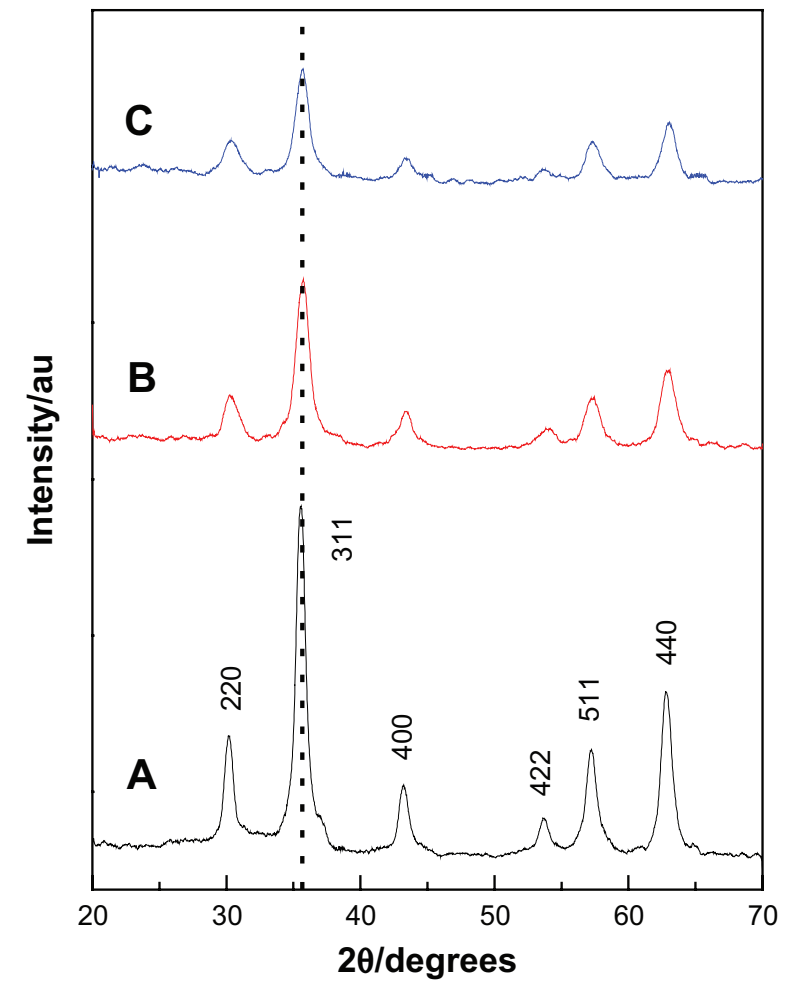

Figure I X-ray diffraction patterns for magnetic nanoparticles (A), chitosan-magnetic nanoparticles (B), and the ampicillin-chitosan-magnetic nanoparticle nanocomposite (C). Abbreviation: au, arbitrary units.

where $\mathrm{D}$ is the mean grain size, $k$ is the Sherrer constant (0.89), $\lambda$ is the X-ray diffraction wavelength $(0.15418 \mathrm{~nm}), \theta$ is the Bragg diffraction angle in degrees, and $\beta$ (in radians) is the full width at half maximum intensity. The diffraction peak that corresponds to the lattice plane (311) at $2 \theta=35.4^{\circ}$ was used for these calculations because this peak was well-resolved, and interferences were not detected. The mean grain sizes for the MNPs and amp-CS-MNPs calculated using this equation were approximately $39.5 \mathrm{~nm}$ and $32.1 \mathrm{~nm}$, respectively.

\section{FTIR}

The FTIR spectra of the MNPs, CS-MNPs, amp-CS-MNPs, and free amp are shown in Figure 2. The MNPs, shown in Figure 2A, produced an absorption peak at $536 \mathrm{~cm}^{-1}$ as a result of $\mathrm{Fe}-\mathrm{O}$ stretching in $\mathrm{Fe}_{3} \mathrm{O}_{4}$. However, this characteristic peak for $\mathrm{Fe}-\mathrm{O}$ was shifted to $541 \mathrm{~cm}^{-1}$ and $545 \mathrm{~cm}^{-1}$ for the CS-MNPs and amp-CS-MNPs, respectively. This result confirms that magnetite nanoparticles were present. Compared with the $\mathrm{Fe}_{3} \mathrm{O}_{4}$ nanoparticles, the $\mathrm{CS}-\mathrm{Fe}_{3} \mathrm{O}_{4}$ spectrum (Figure 2B) included two characteristic peaks for CS at $1,574 \mathrm{~cm}^{-1}$ and $1,064 \mathrm{~cm}^{-1}$, which were a result of $\mathrm{NH}_{3}^{+45}$ and glycosidic bond stretching vibrations, ${ }^{41,46}$ respectively. These characteristic peaks from CS demonstrate that the magnetite nanoparticles were successfully coated with a chitosan polymer.

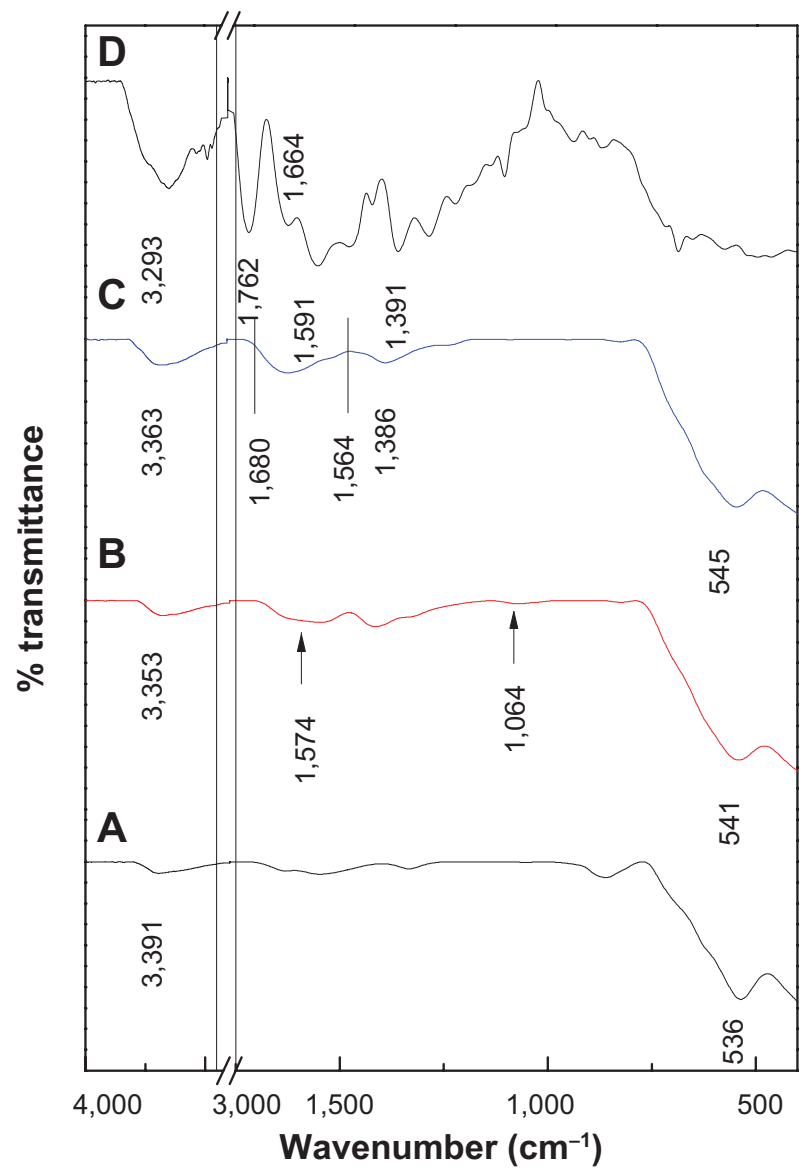

Figure 2 Fourier transform infrared spectra for magnetic nanoparticles (A), chitosan-magnetic nanoparticles (B), ampicillin-chitosan-magnetic nanoparticles (C), and free ampicillin (D).

The FTIR spectrum for amp in Figure 2D shows an absorption peak at $1,762 \mathrm{~cm}^{-1}$, which is caused by $\mathrm{C}=\mathrm{O}$ $\beta$-lactam stretching. ${ }^{47}$ The absorption peak at $1,664 \mathrm{~cm}^{-1}$ was a result of $\mathrm{C}=\mathrm{O}$ amide stretching ${ }^{47}$ and $1,560 \mathrm{~cm}^{-1}$ for $\mathrm{N}-\mathrm{H}$ amide groups. In addition, asymmetric and symmetric stretching vibrations of the carboxylate group appeared at $1,591 \mathrm{~cm}^{-1}$ and $1,391 \mathrm{~cm}^{-1}$, respectively. ${ }^{47}$

The amp peaks in the amp-CS-MNP nanocomposite spectrum in Figure $2 \mathrm{C}$ demonstrate that amp was loaded on the CS-MNP surface. The broad bands at 1,564-1,680 $\mathrm{cm}^{-1}$ were caused by $\mathrm{COO}^{-}$asymmetry, $\mathrm{N}-\mathrm{H}$ amide stretching, and $\mathrm{C}=\mathrm{O}$ $\beta$-lactam stretching from amp. ${ }^{47}$ In addition, the symmetric stretching vibrations of the carboxylate group were shifted to $1,386 \mathrm{~cm}^{-1}$.

Figure 3 shows the interaction between the amp, CS, and MNPs in the amp-CS-MNP nanocomposite, in which the CS polymer and MNPs interacted through a glycosidic bond. The main primary amp species have a protonated carboxylic acid group at the dissolution $\mathrm{pH}(\mathrm{pH}, 4.4-4.6)$ in pure water; a small population with the Zwitterion form is also present 


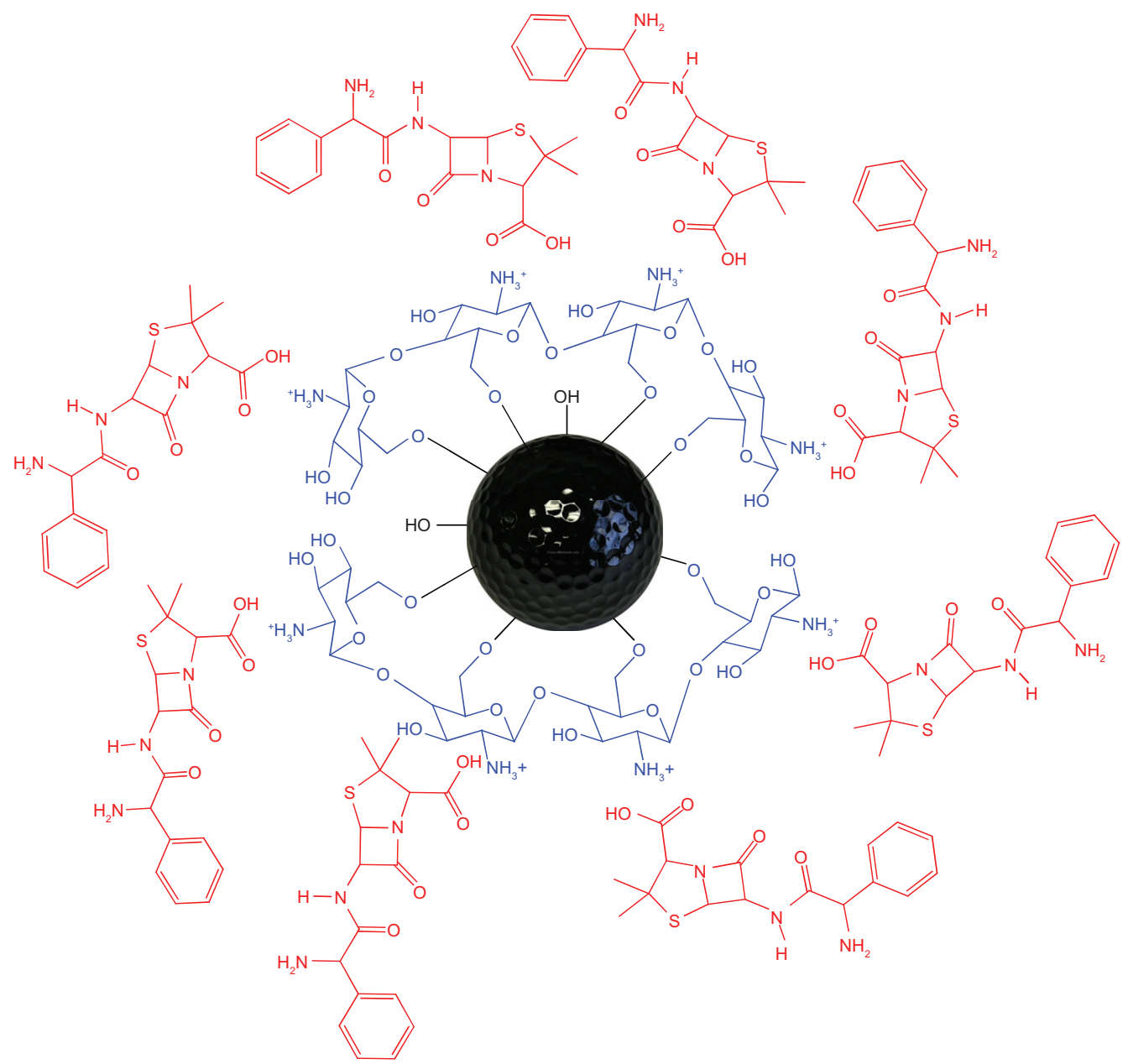

Figure 3 Schematic representation of the interaction between ampicillin, chitosan, and magnetic nanoparticles in the ampicillin-chitosan-magnetic nanoparticle nanocomposite.

(-OOC-R- $\mathrm{NH}_{3}^{+}$), which indicates that the amp and chitosan can interact through a hydrogen bond.

\section{TGA}

Figure 4A-C shows the TGA curves for the MNPs, CS-coated MNPs, and the amp-CS-MNP nanocomposite, respectively. The initial mass loss for the MNPs at temperatures up to $200^{\circ} \mathrm{C}$ may be related to the removal of surface hydroxyl groups and/or adsorbed water. ${ }^{48-50}$ At temperatures higher than $200^{\circ} \mathrm{C}$, the mass loss was $1.9 \%$ for the MNPs and $4.5 \%$ for the CS-MNPs, which may be attributed to amorphous iron hydroxide decomposition followed by iron oxide formation for the former and evaporation followed by decomposition of the CS-MNPs for the latter. By comparing the weight loss curves for the MNPs and CS-MNPs, the quantity of CS coated on the MNPs was estimated at $2.6 \%$.

As shown by the TGA curve for the amp-CS-MNP nanocomposite (Figure 4C), the mass lost at temperatures cooler than $200^{\circ} \mathrm{C}$ was low $(2.9 \%)$ because of the removal

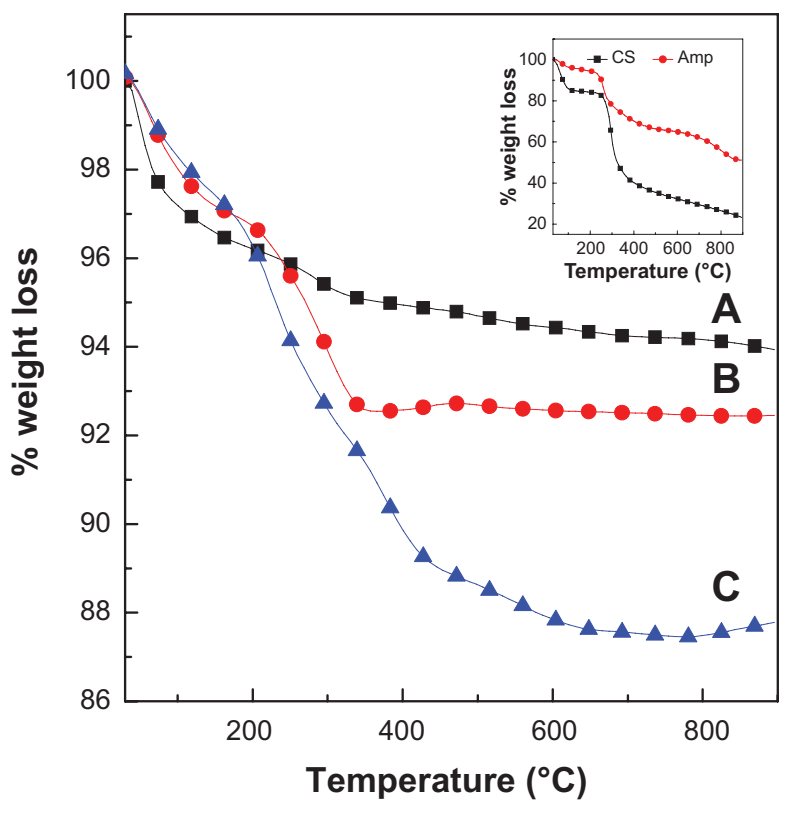

Figure 4 Thermogravimetric data analysis curves for magnetic nanoparticles (A), chitosan-magnetic nanoparticles (B), and ampicillin-chitosan-magnetic nanoparticles (C). The inset shows pure chitosan (CS) and ampicillin (Amp) thermogravimetric curves. 


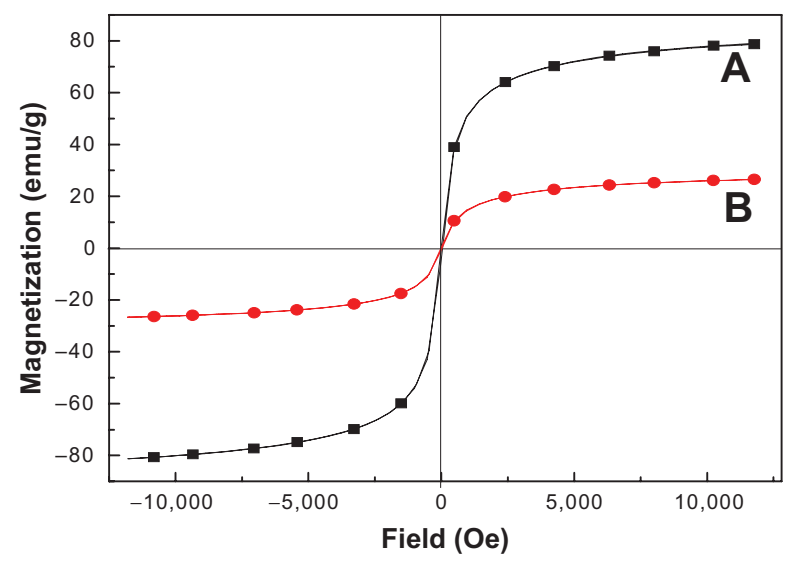

Figure 5 Magnetization curves for magnetic nanoparticles (A) and ampicillinchitosan-magnetic nanoparticles (B), recorded at room temperature.

of the absorbed physical and chemical water. The nanocomposite began to degrade at approximately $200^{\circ} \mathrm{C}$, and final decomposition occurred at approximately $800^{\circ} \mathrm{C}$ (Figure 4), with a $9.3 \%$ total mass loss. The mass loss for the CS-coated MNPs was lower than for the amp-CS-MNP nanocomposite; this result confirms that the amp was loaded onto the CSMNP surface.

The quantity of amp loaded onto the amp-CS-MNP nanocomposite was estimated using carbon, hydrogen, nitrogen, and sulfur analysis. The percentage of sulfur was used to determine the level of loading. The data showed that amp was loaded at $8.3 \%$; this result was close to the ultraviolet data.

\section{Vibrating sample magnetometer}

Figure 5 displays a typical magnetization versus applied magnetic field plot at room temperature. The MNP's magnetization curve (Figure 5A) indicated superparamagnetic behavior resulting from an absent remnance effect with a saturation magnetization of $80.1 \mathrm{emu} / \mathrm{g}$. As shown in Figure 5B, similar to the MNPs, the nanocomposite also indicated a zero remnant magnetization and coercivity; this result suggests that the superparamagnetic behavior is retained for the amp-CS-MNP nanocomposite. However, at $26.6 \mathrm{emu} / \mathrm{g}$, the magnetization value is significantly lower than for the MNPs, indicating that the CS bound to the MNPs and amp was loaded onto the CS-MNP surface.

\section{SEM analyses, average size distribution, and zeta potential}

Figure 6 shows SEM images of the MNPs and the amp-CSMNP nanocomposite at 50,000× magnification. The MNPs exhibit strong agglomeration as a result of the Van der Waals forces among particles. The level of agglomeration decreased for the amp-CS-MNP nanocomposite because of the CS coating.

Figure 7 shows the average size distribution for the MNPs and the amp-CS-MNP nanocomposite, which was determined using dynamic light scattering. The average sizes were $37.8 \mathrm{~nm}$ and $28.2 \mathrm{~nm}$ for the MNPs and amp-CS-MNPs, respectively, which is consistent with the XRD results.

The particle size and size distribution of the MNPs and nanocomposite were calculated using image analysis software. Figure 8 indicates that the MNPs and amp-CS-MNP nanocomposite are spherical. The average size of the MNPs was $40.0 \mathrm{~nm}$ (Figure 8A), and the mean size of the amp-CS-MNP nanocomposite was $26.0 \mathrm{~nm}$ (Figure $8 \mathrm{~B}$ ). It is worth mentioning that the zeta potential for MNPs was $14.4 \mathrm{mV}$ (Figure 9).

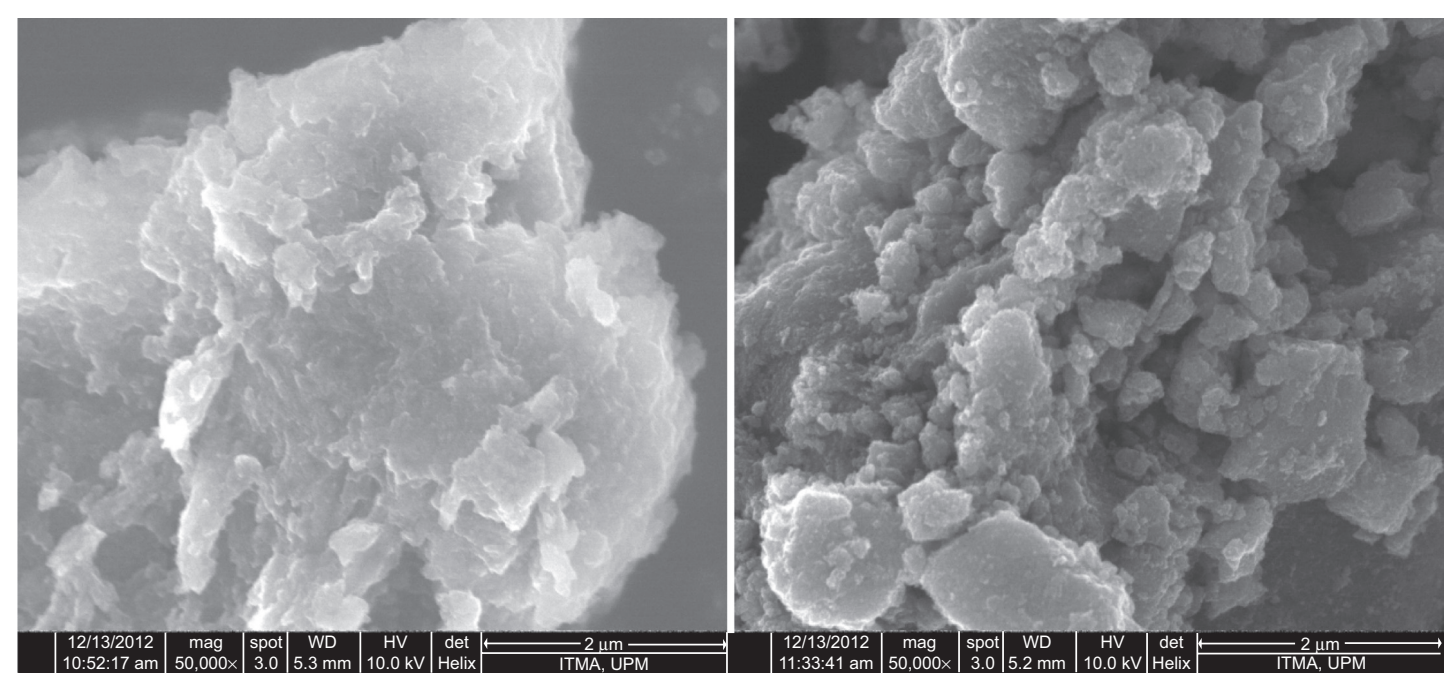

Figure 6 Scanning electron microscope images for magnetic nanoparticles (left) and ampicillin-chitosan-magnetic nanoparticles (right). 


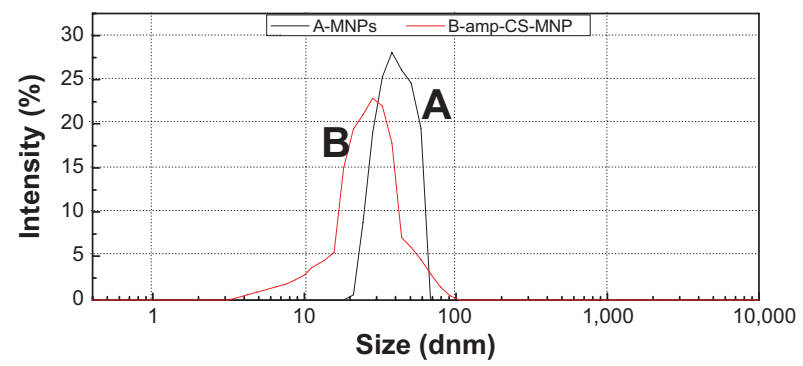

Figure 7 Dynamic light scattering spectra for the magnetic nanoparticles (MNPs) (A) and the ampicillin-chitosan-magnetic nanoparticle (amp-CS-MNP) nanocomposite (B), showing the average particulate size.

\section{In vitro amp release from the amp-CS-MNP nanocomposite}

Amp release profiles for the nanocomposite and a physical mixture with $0.1 \mathrm{M}$ PBS at a pH 7.4 are shown in Figure 10. As shown in the inset of Figure 10, the free amp was quickly released into the PBS solution, and the release was completed within 10 minutes. The nanocomposite amp release rate was clearly lower than that of the free amp, which indicates that the nanocomposite has potential for controlled drug release. This finding may be a result of the electrostatic attraction between the negative charge of the carboxylate group in amp and the chitosan $\mathrm{NH}_{3}^{+}$group.

Amp was released from the nanocomposite, exhibiting fast-release profiles for up to 15 minutes. After incubation with PBS for 400 minutes, the total amp released from the CS-MNPs was $99.6 \%$. The nanocomposite amp release process may be attributed to the ion exchange between the amp anions and the buffer solution anions. ${ }^{51,52}$

\section{Amp release kinetics for the amp-CS-MNP nanocomposite}

The amp release behavior for the amp-CS-MNP nanocomposite can be described using different kinetic models; we used
A

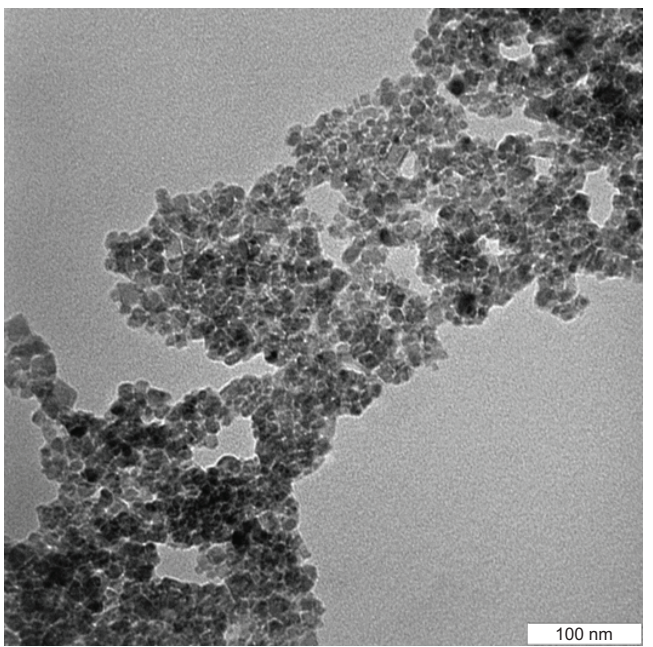

B

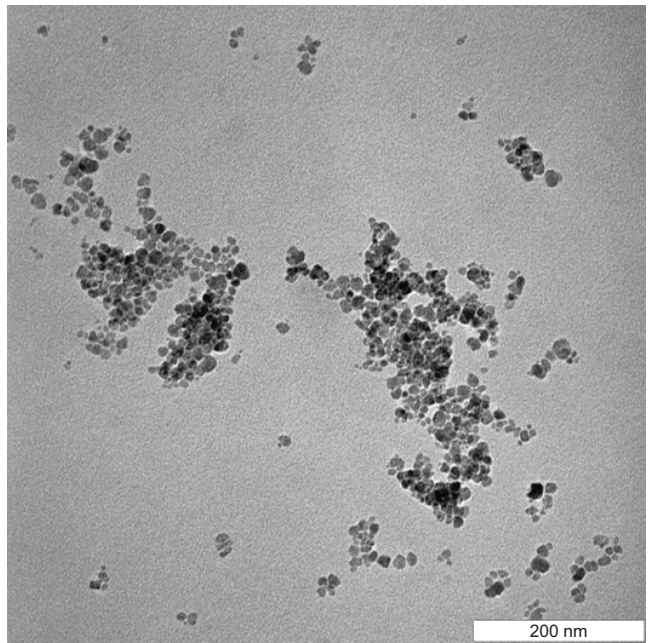

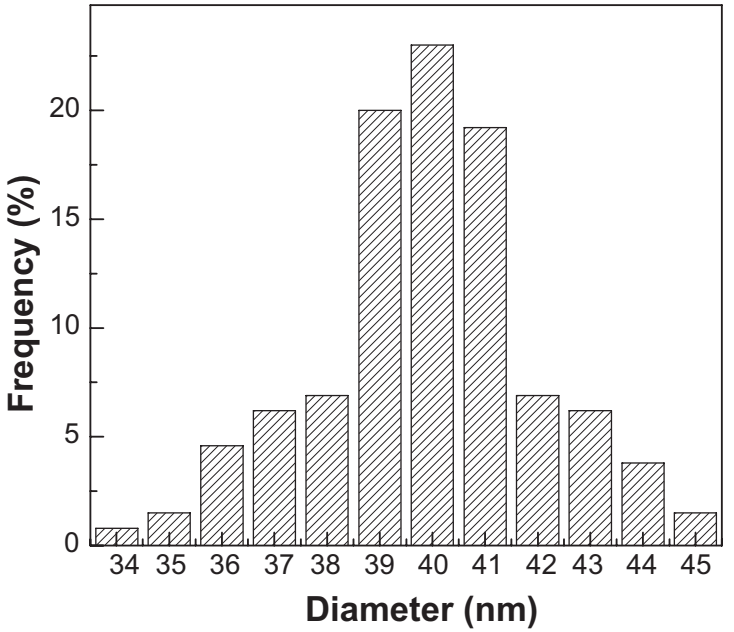

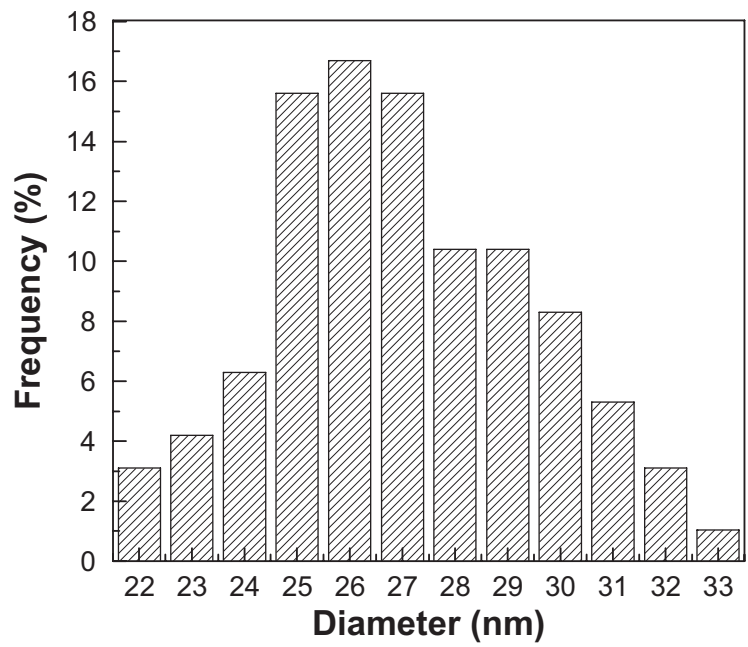

Figure 8 Transmission electron micrographs and corresponding frequency-diameter graphs for the (A) magnetic nanoparticles and (B) ampicillin-chitosan-magnetic nanoparticle nanocomposite. 


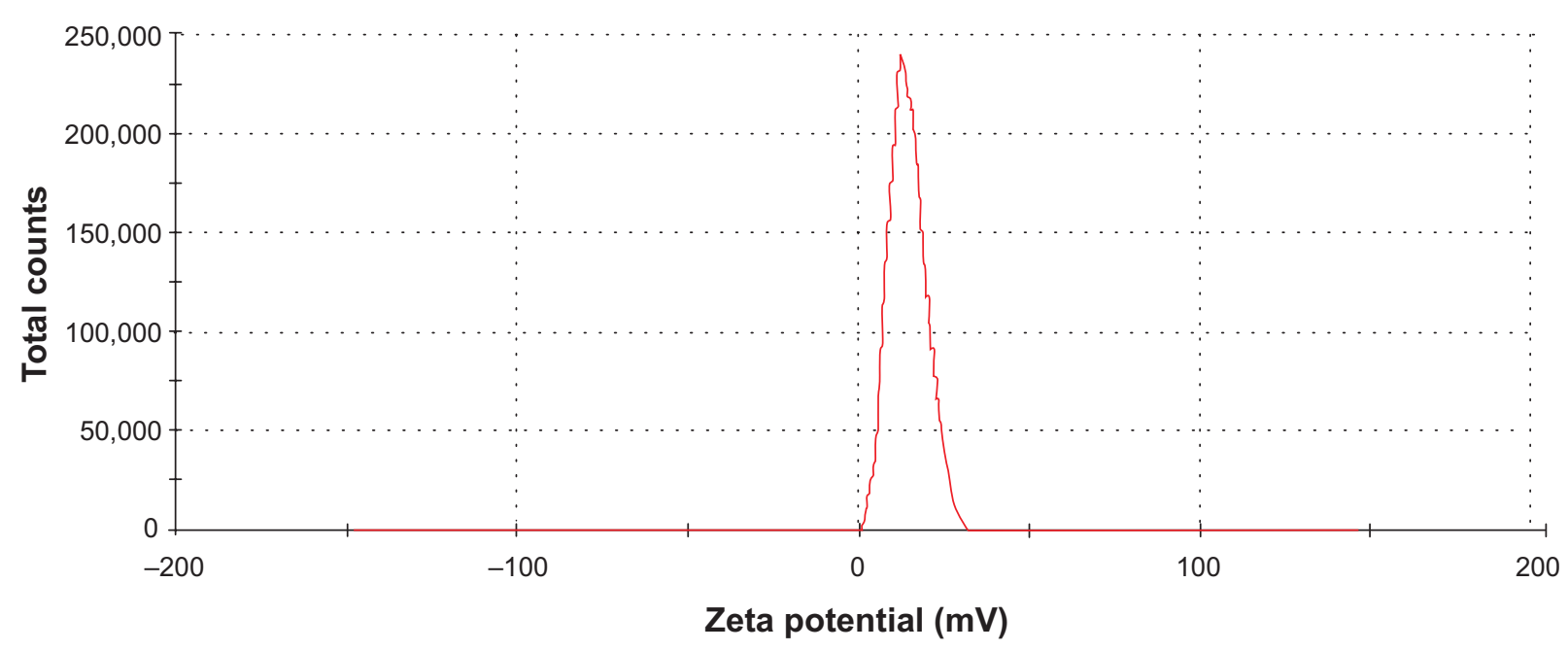

Figure 9 Zeta potential for magnetite nanoparticles.

a pseudo-first-order model (Equation 3), ${ }^{53}$ a pseudo-secondorder model (Equation 4), ${ }^{54}$ the Higuchi model (Equation 5), ${ }^{55}$ the Hixson-Crowell model (Equation 6), ${ }^{55}$ and the KorsmeyerPeppas model (Equation 7): ${ }^{55}$

$$
\begin{gathered}
\operatorname{In}\left(q_{e}-q_{t}\right)=\operatorname{In} q_{e}-k t, \\
t / q_{t}=1 / k q_{e}^{2}+t / q_{e}, \\
q_{t}=k \sqrt{t}, \\
\sqrt[3]{M_{0}}-\sqrt[3]{M_{t}}=k t,
\end{gathered}
$$

and

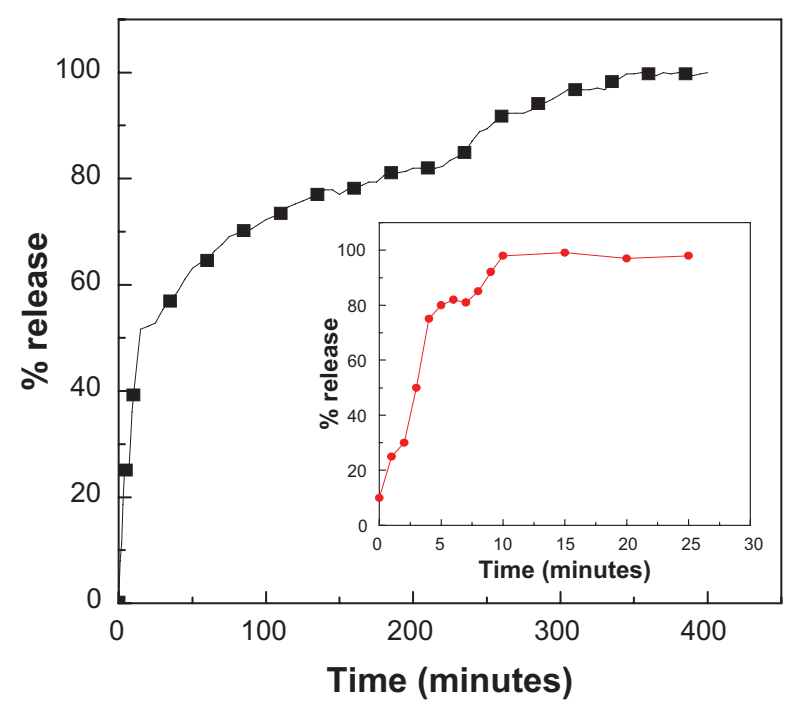

Figure 10 Ampicillin release profiles for the ampicillin-chitosan-magnetic nanoparticle nanocomposite at $\mathrm{pH}$ 7.4. Inset: ampicillin release profiles for the physical mixture.

$$
\frac{q_{t}}{q_{\infty}}=k t^{n},
$$

where $q_{e}$ and $q_{t}$ are the equilibrium release quantities and the quantities released at any time $t$, respectively. $M_{0}$ and $M_{t}$ are the initial quantity and the quantity in the nanocomposite at time $t$, respectively. $k$ is the rate constant. Using the five kinetic models and the kinetic amp release data, we observed that the pseudo-second-order model best described the kinetic amp release processes from the amp-CS-MNP nanocomposite, with a correlation coefficient of 0.9856 . Figure 11 shows the plots for the five kinetic models; the correlation coefficients are listed in Table 1.

\section{In vitro antimicrobial activity of the amp-CS-MNP nanocomposite}

In the present study, the antimicrobial activity of the synthesized amp-CS-MNP nanocomposite was determined using five clinically significant bacterial strains known to cause a range of minor to life-threatening skin, burn, respiratory, urinary tract, gastrointestinal, and blood infections. The antibacterial activity was indicated by a clear zone of inhibition around the well inside the agar plate. The zone of inhibition diameters for the amp-CSMNP nanocomposite is shown in Table 2, which indicates that the synthesized amp-CS-MNP nanocomposite maintains antibacterial activities against Gram-positive and Gram-negative bacteria (Figure 12). The CS-MNPs were screened, using the bacteria, and did not display an inhibitory zone, indicating that the antibacterial activity was a result of the slow release of loaded amp from the amp-CS-MNP nanocomposite. 

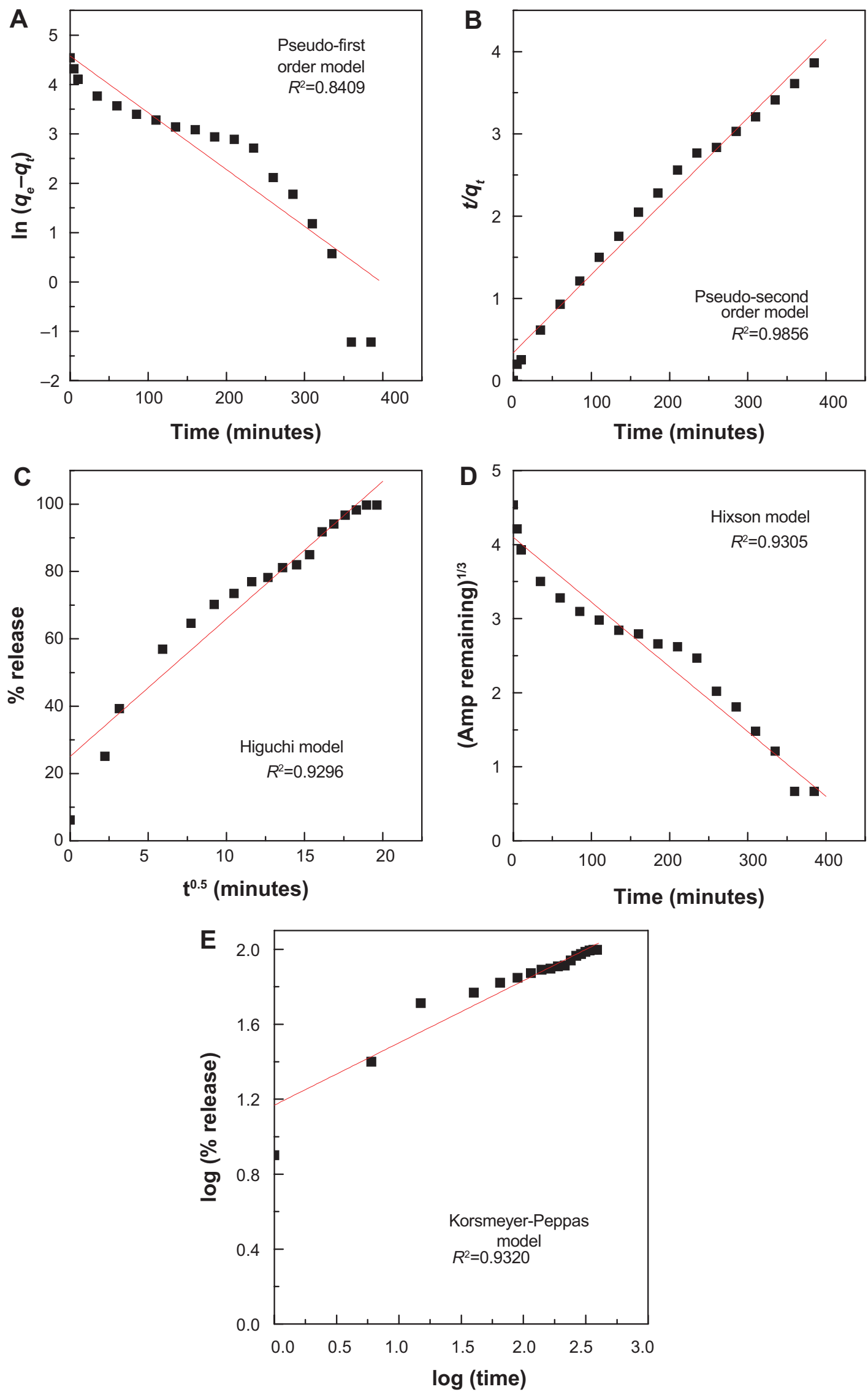

Figure I I Fitting ampicillin release data for the ampicillin-chitosan-magnetic nanoparticle nanocomposite, using different kinetic models (A-E) at pH 7.4. Abbreviations: Amp, ampicillin; log, natural logarithm; $t$, time. 
Table I Correlation coefficients $\left(R^{2}\right)$ obtained by fitting ampicillin release data for the ampicillin-chitosan-magnetic nanoparticle nanocomposite in phosphate-buffered saline solution at $\mathrm{pH} 7.4$

\begin{tabular}{lllllll}
\hline Sample & $\begin{array}{l}\text { Saturation } \\
\text { release, \% }\end{array}$ & $\begin{array}{l}\text { Pseudo-first } \\
\text { order model }\end{array}$ & $\begin{array}{l}\text { Pseudo-second } \\
\text { order model }\end{array}$ & $\begin{array}{l}\text { Higuchi } \\
\text { model }\end{array}$ & $\begin{array}{l}\text { Hixson-Crowell } \\
\text { model }\end{array}$ & $\begin{array}{l}\text { Korsmeyer- } \\
\text { Peppas model }\end{array}$ \\
\hline $\begin{array}{l}\text { Ampicillin-chitosan-magnetic } \\
\text { nanoparticles }\end{array}$ & 99.7 & 0.8409 & 0.9856 & 0.9296 & 0.9305 & 0.9320 \\
\hline
\end{tabular}

The microbial growth inhibition experiment ascertained the antimicrobial effect of the amp-CS-MNP nanocomposite against the tested microorganisms, as shown in Figure 13. Interestingly, the amp-CS-MNP nanocomposite showed antifungal activity, as demonstrated by its growth inhibitory effect on Candida albicans. The MIC determination showed that the amp-CS-MNP nanocomposite had MIC values of $23.4 \mathrm{mg}, 0.5 \mathrm{mg}$, and $1 \mathrm{mg}$ and $1.1 \mu \mathrm{g} / \mathrm{mL}$ against S. aureus $\left(\mathrm{ATCC}^{\circledR} 43300^{\mathrm{TM}}\right)$, P. aeruginosa $\left(\mathrm{ATCC}^{\circledR} 27853^{\mathrm{TM}}\right)$, E. coli $\left(\right.$ ATCC $^{\circledR} 25922^{\mathrm{TM}}$ ), and C. albicans $\left(\right.$ ATCC $^{\circledR} 20408^{\mathrm{TM}}$ ), respectively. Although amp is an antibacterial antibiotic, the amp-CS-MNP nanocomposite showed activity against $C$. albicans. This can be explained by the fact that the activity of the amp-CS-MNP nanocomposite against $C$. albicans might be attributed to the chitosan and the MNP components of the nanocomposite. Chitosan is known to show antifungal and antibacterial activity. The antifungal activity of the amp-CS-MNP nanocomposite warrants further mechanistic investigation.

The BBL ${ }^{\text {TM }}$ MGIT $^{\text {TM }} 960$ system experiment demonstrated that the amp-CS-MNP nanocomposite showed antimycobacterial activity against $M$. tuberculosis, as shown in Figure 14, with an MIC value of $801 \mu \mathrm{g} / \mathrm{mL}$ compared with the three first-line antituberculosis drugs (isonicotinic acid hydrazide, 4-aminosalicylic acid, and pyrazinamide), which showed MIC values of $2.3 \mu \mathrm{g} / \mathrm{mL}, 5.0 \mu \mathrm{g} / \mathrm{mL}$, and $435 \mu \mathrm{g} / \mathrm{mL}$, respectively. Although it is reported that Mycobacteria species showed intrinsic resistance to amp, the activity of the nanocomposite might be explained by the presence of the other components of the amp-CS-MNP nanocomposite that might have synergistic effects with

Table 2 Antimicrobial activity of ampicillin-chitosan-magnetic nanoparticle nanocomposite against different microorganisms, as determined using the agar diffusion method*

\begin{tabular}{llllll}
\hline Compound/microorganism & EC & SC & PA & MRSA & BS \\
\hline Ampicillin & 24 & 24 & 22 & 26 & 30 \\
Ampicillin-chitosan-magnetic & II & II & I3 & II & 14 \\
nanoparticle nanocomposite & & & & &
\end{tabular}

Notes: *The zone of inhibition diameters were measured to the nearest millimeter. Abbreviations: EC, Escherichia coli; SC, Salmonella choleraesuis; PA, Pseudomonas aeruginosa; MRSA, methicillin-resistant Staphylococcus aureus; BS, Bacillus subtilis. amp. The MIC of the amp-CS-MNP nanocomposite against tuberculosis was high and was approximately twice the MIC value of that of pyrazinamide; however, the important fact is that the nanocomposite showed an inhibitory effect on M. tuberculosis.

Notably, chitosan has intrinsic antimicrobial effects that depend on different factors, such as the polymerization and deacetylation levels, molecular weight, solvent, target microorganisms, and physicochemical characteristics, and it is inversely affected by $\mathrm{pH} .{ }^{56}$ Further investigation into the molecular mechanisms for both the CS-MNPs and the amp-CS-MNP nanocomposite may reveal an additional synergistic antimicrobial effect. In addition, the stability of the amp-CS-MNP nanocomposite in the presence of bacterial antibiotic-destroying enzymes must be determined; $\beta$-lactamases (penicillinases) will be important for applying this nanoantibiotic to treat $\beta$-lactamase-mediated resistant bacteria in serious infections.

\section{Conclusion and future perspectives}

Nanotechnology offers various opportunities to restore efficacy to currently used antibiotic antimicrobial agents and to bypass the arsenal of microbial pathogen-resistance mechanisms. Thus, we synthesized superparamagnetic iron oxide nanoparticles coated with chitosan and loaded with amp; both the MNPs and the amp-CS-MNP nanocomposite exhibited saturation magnetization at $80.1 \mathrm{emu} / \mathrm{g}$ and $26.6 \mathrm{emu} / \mathrm{g}$, respectively. The amp release was also studied, and the total amp release equilibrium for the CS-MNPs was $100 \%$ in 400 minutes.

Advances in nanotechnology have facilitated the design and chemotherapeutic engineering of new nanoantibiotics and nonantibiotic (disinfectants and antiseptics) antimicrobial agents for use in pharmaceutical applications for counteracting global public health threats resulting from antimicrobial-resistant pathogens. ${ }^{26,29,30,57}$ In addition to current research studies aimed at improving the available antibiotics, using semisynthetic chemical modifications to develop new generations of antibiotics with enhanced activity and greater stability against bacterial resistance mechanisms, antibiotic-polymer-based nanoparticles ("nano-antibiotics" or "nanobiotics"; the terms 

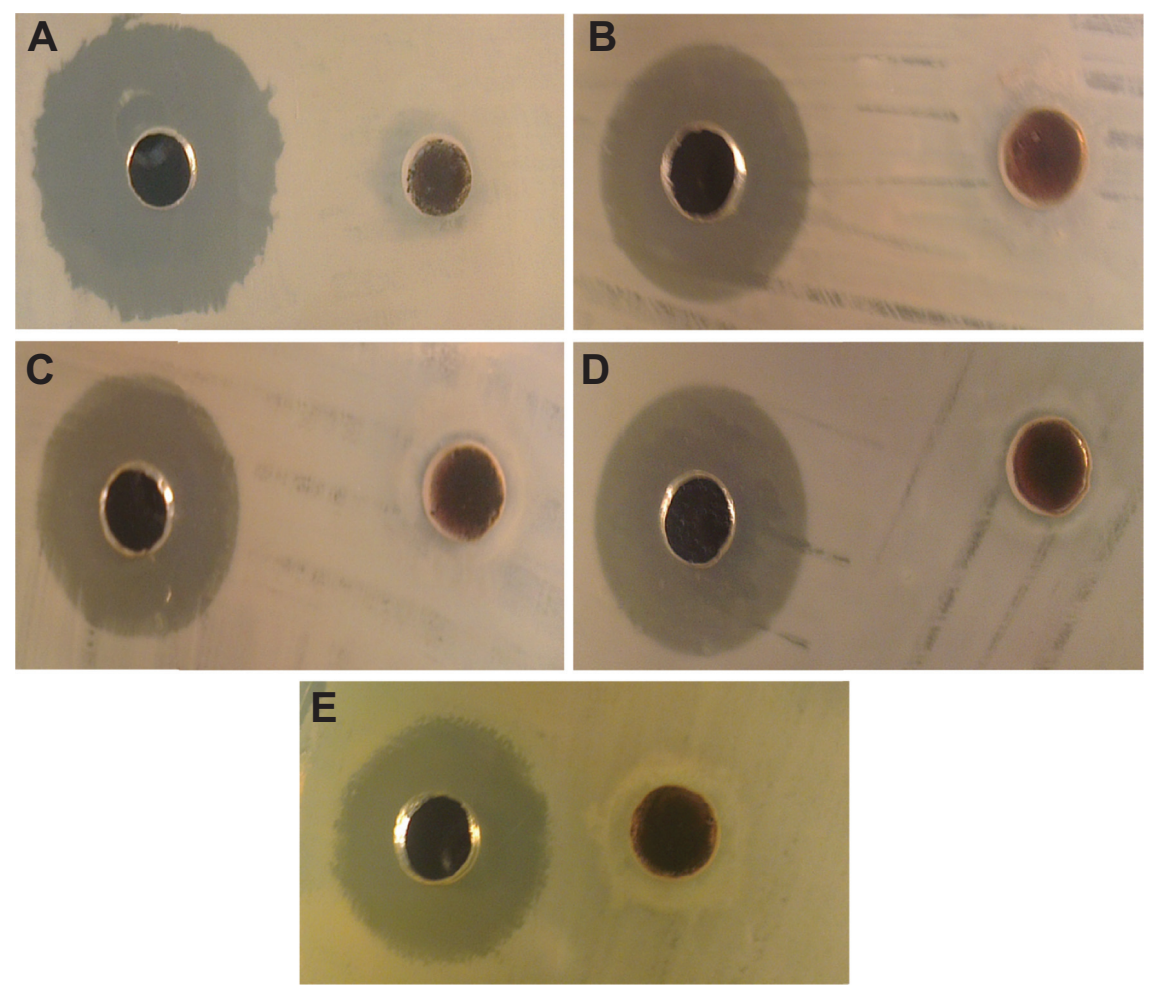

Figure 12 Antimicrobial activity of the ampicillin-chitosan-magnetic nanoparticle nanocomposite, determined using the agar diffusion method.

Notes: Photographs of (A) Bacillus subtilis, (B) methicillin-resistant Staphylococcus aureus (C), Salmonella choleraesuis (D), Escherichia coli, and (E) Pseudomonas aeruginosa. The left-side wells contain free antibiotics, and the right-side wells contain the nanoantibiotic (ampicillin-chitosan-magnetic nanoparticle nanocomposite).
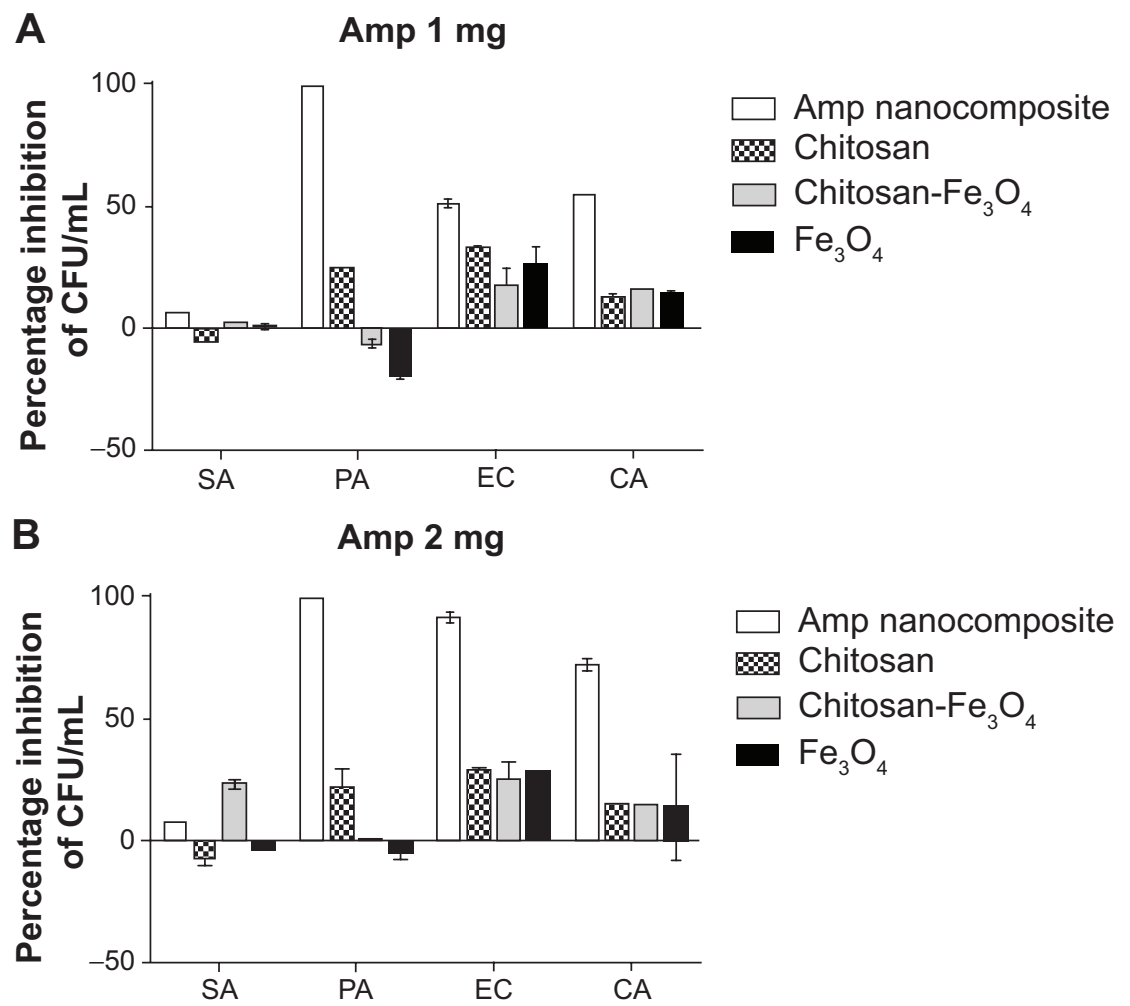

Figure 13 (A, B) Microbial growth inhibition rates of the ampicillin-chitosan-magnetic nanoparticle nanocomposite compared with the individual components of the nanocomposite against Staphylococcus aureus (SA) (ATCC ${ }^{\otimes} 43300^{\mathrm{TM}}$ ), Pseudomonas aeruginosa (PA) (ATCC ${ }^{\circledR} 27853^{\mathrm{TM}}$ ), Escherichia coli (EC) (ATCC ${ }^{\circledR 25922}{ }^{\mathrm{TM}}$ ), Candida albicans (CA) (ATCC ${ }^{\circledR} 20408^{\mathrm{TM}}$ ), at two different concentrations of ampicillin-chitosan-magnetic nanoparticle nanocomposite against different microorganisms, respectively. All cultures were sourced from the American Type Culture Collection, Manassas, VA, USA.

Abbreviations: ATCC, American Type Culture Collection; Amp, ampicillin; CFU, colony forming units. 


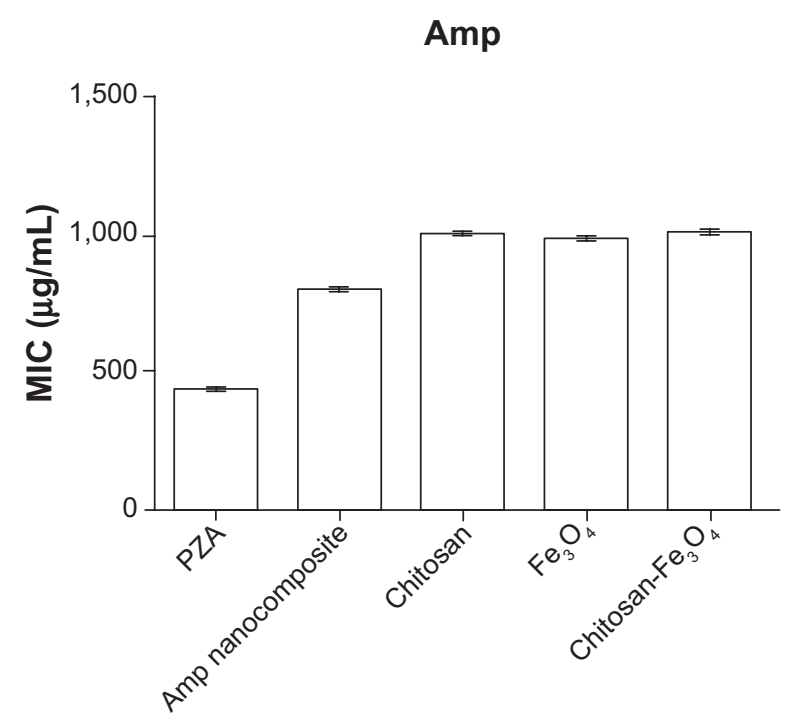

\section{Compounds and nanocomposites tested}

Figure 14 Minimum inhibitory concentration of ampicillin-chitosan-magnetic nanoparticle nanocomposite in comparison with other antituberculosis antimicrobial agents against Mycobacterium tuberculosis, using the Bactec ${ }^{\mathrm{TM}} \mathrm{BBL}^{\mathrm{TM}}$ Mycobacteria Growth Indicator Tube (MGITTM) 960 system (Becton Dickinson and Company, Franklin Lakes, NJ, USA).

Abbreviations: Amp, ampicillin; MIC, minimum inhibitory concentration; PZA pyrazinamide.

are used interchangeably) was recently introduced. ${ }^{26,58-60} \mathrm{New}$ nanotechnology-based antimicrobial chemotherapeutic agents, particularly for bacterial infections, are under development and represent a major breakthrough in nanomedicine that requires further studies on their possible toxicity, in vivo release, and mechanisms underlying their enhanced or equipotent antibacterial effects for clinically efficacious nanobiotic used in treating infectious diseases.

\section{Acknowledgments}

The authors thank the Ministry of Higher Education of Malaysia, which (under grant 05-03-10-1035 Research University Grant Scheme [RUGS; vote 9199644]) provided funding for this research. The authors are also grateful to Northeastern University for funding part of the microbiological experiments.

\section{Disclosure}

The authors report no conflicts of interest in this work.

\section{References}

1. Prodan D, Chanéac C, Tronc E, et al. Adsorption phenomena and magnetic properties of $\gamma-\mathrm{Fe}_{2} \mathrm{O}_{3}$ nanoparticles. J Magnetism Magnetic Mater. 1999;203:63-65.

2. Prodan D, Grecu VV, Grecu MN, Tronc E, Jolivet JP. Electron spin resonance in $\gamma-\mathrm{Fe}_{2} \mathrm{O}_{3}$ nanoparticles dispersed in a polymer matrix. Measurement Sci Technol. 1999;10(9):L41-L43.

3. Predoi D, Kuncser V, Filoti G. Magnetic behaviour of maghemite nanoparticles studied by Mössbauer spectroscopy. Rom Rep Phys. 2004; 56(3):373-378.
4. Parveen S, Misra R, Sahoo SK. Nanoparticles: a boon to drug delivery, therapeutics, diagnostics and imaging. Nanomedicine. 2012;8(2): $147-166$.

5. Laurent S, Forge D, Port M, et al. Magnetic iron oxide nanoparticles: synthesis, stabilization, vectorization, physicochemical characterizations, and biological applications. Chem Rev. 2008;108(6):2064-2110.

6. Oka H, Tomioka T, Tomita $\mathrm{K}$, Nishino A, Ueda S. Inactivation of enveloped viruses by a silver-thiosulfate complex. Met Based Drugs. 1994;1(5-6):511.

7. Mahmoudi M, Sant S, Wang B, Laurent S, Sen T. Superparamagnetic iron oxide nanoparticles (SPIONs): development, surface modification and applications in chemotherapy. Adv Drug Deliv Rev. 2011;63(1-2): $24-46$.

8. Arbab AS, Bashaw LA, Miller BR, et al. Characterization of biophysical and metabolic properties of cells labeled with superparamagnetic iron oxide nanoparticles and transfection agent for cellular MR imaging. Radiology. 2003;229(3):838-846.

9. Jing XH, Yang L, Duan XJ, et al. In vivo MR imaging tracking of magnetic iron oxide nanoparticle labeled, engineered, autologous bone marrow mesenchymal stem cells following intra-articular injection. Joint Bone Spine. 2008;75(4):432-438.

10. Fortin JP, Wilhelm C, Servais J, Ménager C, Bacri JC, Gazeau F. Size-sorted anionic iron oxide nanomagnets as colloidal mediators for magnetic hyperthermia. J Am Chem Soc. 2007;129(9): $2628-2635$.

11. Mahmoudi M, Shokrgozar MA, Simchi A, et al. Multiphysics flow modeling and in vitro toxicity of iron oxide nanoparticles coated with polyvinyl alcohol. J Phys Chem C. 2009;113:2322-2331.

12. Lübbe AS, Bergemann C, Huhnt W, et al. Preclinical experiences with magnetic drug targeting: tolerance and efficacy. Cancer Res. 1996; 56(20):4694-4701.

13. Lübbe AS, Bergemann C, Riess H, et al. Clinical experiences with magnetic drug targeting: a phase I study with $4^{\prime}$-epidoxorubicin in 14 patients with advanced solid tumors. Cancer Res. 1996;56(20): 4686-4693.

14. Ball AP, Bartlett JG, Craig WA, et al. Future trends in antimicrobial chemotherapy: expert opinion on the 43rd ICAAC. J Chemother. 2004; 16(5):419-436.

15. Suárez C, Gudiol F. [Beta-lactam antibiotics]. Enferm Infecc Microbiol Clin. 2009;27(2):116-129. Spanish.

16. Fleming A. On the antibacterial action of cultures of a penicillium, with special reference to their use in the isolation of B. influenzae. 1929. Bull World Health Organ. 2001;79(8):780-790.

17. Rolinson GN. Forty years of beta-lactam research. $J$ Antimicrob Chemother. 1998;41(6):589-603.

18. Rolinson GN, Stevens S. Microbiological studies on a new broadspectrum penicilin, "Penbritin". Br Med J. 1961;2(5246):191-196.

19. Stewart GT, Coles HM, Nixon HH, Holt RJ. "Penbritin": An Oral Penicillin with Broad-spectrum Activity. Br Med J. 1961;2(5246): 200-206.

20. Hawkey PM. The origins and molecular basis of antibiotic resistance. BMJ. 1998;317(7159):657-660.

21. Davies J, Davies D. Origins and evolution of antibiotic resistance Microbiol Mol Biol Rev. 2010;74(3):417-433.

22. Arias CA, Murray BE. Antibiotic-resistant bugs in the 21 st century - a clinical super-challenge. $N$ Engl J Med. 2009;360(5):439-443.

23. Butler MS, Cooper MA. Antibiotics in the clinical pipeline in 2011. J Antibiot (Tokyo). 2011;64(6):413-425.

24. Wright GD. Antibiotics: a new hope. Chem Biol. 2012;19(1):3-10.

25. Allahverdiyev AM, Kon KV, Abamor ES, Bagirova M, Rafailovich M. Coping with antibiotic resistance: combining nanoparticles with antibiotics and other antimicrobial agents. Expert Rev Anti Infect Ther. 2011; 9(11):1035-1052.

26. Huh AJ, Kwon YJ. "Nanoantibiotics": a new paradigm for treating infectious diseases using nanomaterials in the antibiotics resistant era. $J$ Control Release. 2011;156(2):128-145.

27. Taubes G. The bacteria fight back. Science. 2008;321(5887): 356-361. 
28. Bell IR, Schwartz GE, Boyer NN, Koithan M, Brooks AJ. Advances in Integrative Nanomedicine for Improving Infectious Disease Treatment in Public Health. Eur J Integr Med. 2013;5(2):126-140.

29. Matthews L, Kanwar RK, Zhou S, Punj V, Kanwar JR. Applications of nanomedicine in antibacterial medical therapeutics and diagnostics. Open Tropical Med J. 2010;3:1-9.

30. Seil JT, Webster TJ. Antimicrobial applications of nanotechnology: methods and literature. Int J Nanomedicine. 2012;7:2767-2781.

31. Oloffs A, Grosse-Siestrup C, Bisson S, Rinck M, Rudolph R, Gross U. Biocompatibility of silver-coated polyurethane catheters and silvercoated Dacron material. Biomaterials. 1994;15(10):753-758.

32. Flores M, Colon N, Rivera O, et al. A study of the growth curves of C. xerosis and E. coli bacteria in mediums containing cobalt ferrite nanoparticles. Mat Res Soc Symp Proc. 2004;820:227-234.

33. Williams DN, Ehrman SH, Pulliam Holoman TR. Evaluation of the microbial growth response to inorganic nanoparticles. J Nanobiotechnology. 2006;4:3.

34. Fattal E, Youssef M, Couvreur P, Andremont A. Treatment of experimental salmonellosis in mice with ampicillin-bound nanoparticles. Antimicrob Agents Chemother. 1989;33(9):1540-1543.

35. Forestier F, Gerrier P, Chaumard C, Quero AM, Couvreur P, Labarre C. Effect of nanoparticle-bound ampicillin on the survival of Listeria monocytogenes in mouse peritoneal macrophages. J Antimicrob Chemother. 1992;30(2):173-179.

36. Balland O, Pinto-Alphandary H, Pecquet S, Andremont A, Couvreur P. The uptake of ampicillin-loaded nanoparticles by murine macrophages infected with Salmonella typhimurium. J Antimicrob Chemother. 1994; 33(3):509-522.

37. Pinto-Alphandary H, Andremont A, Couvreur P. Targeted delivery of antibiotics using liposomes and nanoparticles: research and applications. Int J Antimicrob Agents. 2000;13(3):155-168.

38. Misra R, Acharya S, Dilnawaz F, Sahoo SK. Sustained antibacterial activity of doxycycline-loaded poly(D,L-lactide-co-glycolide) and poly(epsilon-caprolactone) nanoparticles. Nanomedicine (Lond). 2009; 4(5):519-530.

39. Obonyo M, Zhang L, Thamphiwatana S, Pornpattananangkul D, Fu V, Zhang L. Antibacterial activities of liposomal linolenic acids against antibiotic-resistant Helicobacter pylori. Mol Pharm. 4, 2012;9(9): 2677-2685.

40. Predoi D. A study on iron oxide nanoparticles coated with dextrin obtained by coprecipitation. Dig J Nanomater Biostruct. 2007;2: 169-173.

41. Inbaraj BS, Tsai T-Y, Chen B-H. Synthesis, characterization and antibacterial activity of superparamagnetic nanoparticles modified with glycol chitosan. Sci Technol Adv Mater. 2012;13(2012):015002.

42. Clinical and Laboratory Standards Institute. Performance standards for antimicrobial susceptibility testing: eighteenth informational supplement. Wayne, PA, USA: Clinical and Laboratory Standards Institute; 2008.

43. Usman MS, El Zowalaty ME, Shameli K, Zainuddin N, Salama M, Ibrahim NA. Synthesis, characterization, and antimicrobial properties of copper nanoparticles. Int J Nanomedicine. 2013:8:4467-4479.

44. Glover AL, Bennett JB, Pritchett JS, et al. Magnetic Heating of Iron Oxide Nanoparticles and Magnetic Micelles for Cancer Therapy. IEEE Trans Magn. 2013;49(1):231-235.

International Journal of Nanomedicine

\section{Publish your work in this journal}

The International Journal of Nanomedicine is an international, peerreviewed journal focusing on the application of nanotechnology in diagnostics, therapeutics, and drug delivery systems throughout the biomedical field. This journal is indexed on PubMed Central, MedLine, CAS, SciSearch ${ }^{\circledR}$, Current Contents ${ }^{\circledR} /$ Clinical Medicine,
45. Silva SML, Braga CRC, Fook MVL, et al. Application of infrared spectroscopy to analysis of chitosan/clay nanocomposite. In: Infrared Spectroscopy - Materials Science, Engineering and Technology. Theophile T, editor. Rijeka, Croatia: InTech; 2012.

46. Qu JB, Shao HH, Jing GL, Huang F. PEG-chitosan-coated iron oxide nanoparticles with high saturated magnetization as carriers of 10-hydroxycamptothecin: preparation, characterization and cytotoxicity studies. Colloids Surf B Biointerfaces. 2013;102:37-44.

47. Trikeriotis M, Ghanotakis DF. Intercalation of hydrophilic and hydrophobic antibiotics in layered double hydroxides. Int J Pharm. 2007; 332(1-2):176-184.

48. Inbaraj BS, Kao TH, Tsai TY, Chiu CP, Kumar R, Chen BH. The synthesis and characterization of poly $(\gamma$-glutamic acid)-coated magnetite nanoparticles and their effects on antibacterial activity and cytotoxicity. Nanotechnology. 2011;22(7):075101.

49. Kumar R, Inbaraj BS, Chen BH. Surface modification of superparamagnetic iron nanoparticles with calcium salt of poly ( $\gamma$-glutamic acid) as coating material. Mater Res Bull. 2010;45:1603-1607.

50. Shan Z, Yang W-S, Zhang X, Huang Q-M, Ye H. Preparation and characterization of carboxyl-group functionalized superparamagnetic nanoparticles and the potential for bio-applications. J Braz Chem Soc. 2007; 18:1329-1335.

51. Ambrogi V, Fardella G, Grandolini G, Perioli L, Tiralti MC. Intercalation compounds of hydrotalcite-like anionic clays with antiinflammatory agents, II: Uptake of diclofenac for a controlled release formulation. AAPS Pharm Sci Tech. 2002;3(3):E26.

52. bin Hussein MZ, Zainal Z, Yahaya AH, Foo DW. Controlled release of a plant growth regulator, alpha-naphthaleneacetate from the lamella of Zn-Al-layered double hydroxide nanocomposite. J Control Release. 2002;82(2-3):417-427.

53. Dong L, Yan L, Hou W-G, Liu S-J. Synthesis and release behavior of composites of camptothecin and layered double hydroxide. J Solid State Chem. 2010;183(8):1811-1816.

54. Ho YS, Ofomaja AE. Pseudo-second-order model for lead ion sorption from aqueous solutions onto palm kernel fiber. J Hazard Mater. 2006;129(1-3):137-142.

55. Sakore S, Chakraborty B. Formulation and evaluation of enalapril maleate sustained release matrix tablets. Int J Pharm. 2013;4:21-26.

56. Goy RC, Britto D, Assis OBG. A review of the antimicrobial activity of chitosan. Polimeros: Cie Tec. 2009;3:1-7. Available at: http://www.scielo.br/scielo.php?script=sci_arttext\&pid=S0104-14282009000300013. Accessed June 11, 2014.

57. Hajipour MJ, Fromm KM, Ashkarran AA, et al. Antibacterial properties of nanoparticles. Trends Biotechnol. 2012;30(10):499-511.

58. Yacoby I, Benhar I. Antibacterial nanomedicine. Nanomedicine (Lond). 2008;3(3):329-341.

59. Abeylath SC, Turos E, Dickey S, Lim DV. Glyconanobiotics: Novel carbohydrated nanoparticle antibiotics for MRSA and Bacillus anthracis. Bioorg Med Chem. 2008;16(5):2412-2418.

60. Saúde AC, Cherobim MD, Amaral AC, Dias SC, Franco OL. Nanoformulated antibiotics: the next step for pathogenic bacteria control. Curr Med Chem. 2013;20(10):1232-1240.

Journal Citation Reports/Science Edition, EMBase, Scopus and the Elsevier Bibliographic databases. The manuscript management system is completely online and includes a very quick and fair peer-review system, which is all easy to use. Visit http://www.dovepress.com/ testimonials.php to read real quotes from published authors. 